\title{
Are UK junior doctors doing the right thing?
}

$\mathrm{F}$ ollowing months of contract negotiations, junior doctors in the United Kingdom are striking on three nonconsecutive days, beginning Jan. 12. Of the 37000 registered junior doctor members of the British Medical Association (BMA), 98\% voted in November to strike over changes to pay rates and conditions that they say devalue weekend and evening work.

Under the European Convention on Human Rights (Article 11), doctors have the right to join a trade union and "the right to freedom of peaceful assembly." The BMA's strike guidelines for junior doctors remind them that the strike is legal. But is it ethical?

The General Medical Council (GMC), which sets standards for physicians and trainees, lists "Duties of a Doctor" similar to the Canadian Medical Association's (CMA's) Code of Ethics, including the familiar "Make the care of your patient your first concern." Further, Article 11 in the European Convention on Human Rights states that "in the interests of national security or public safety" there may be restrictions on exercising the right to strike "for the protection of health," among other reasons.

Will the junior doctors' strike cause lack of care, or worse, harm to patients?

This argument is used by those opposing the strike. Secretary of State for Health Jeremy Hunt's Jan. 4 public letter to the BMA Council Chair urged a return to negotiations: "Any strike action risks serious harm to patients." Bruce Keogh, medical director for NHS England, went further, asking if the BMA had a contingency plan for a terrorist attack.

The BMA is taking steps to ensure patient safety during the strike. During the 24-hour Jan. 12 strike, junior doctors are working in emergency care as scheduled, and will do so again during part two of the strike, which will last 48 hours starting Jan. 26. On Feb. 10, the third day of action, they will not work at all for nine hours. However, with three times as many senior doctors as juniors, there should be enough consultants to cover emergency departments and criti-

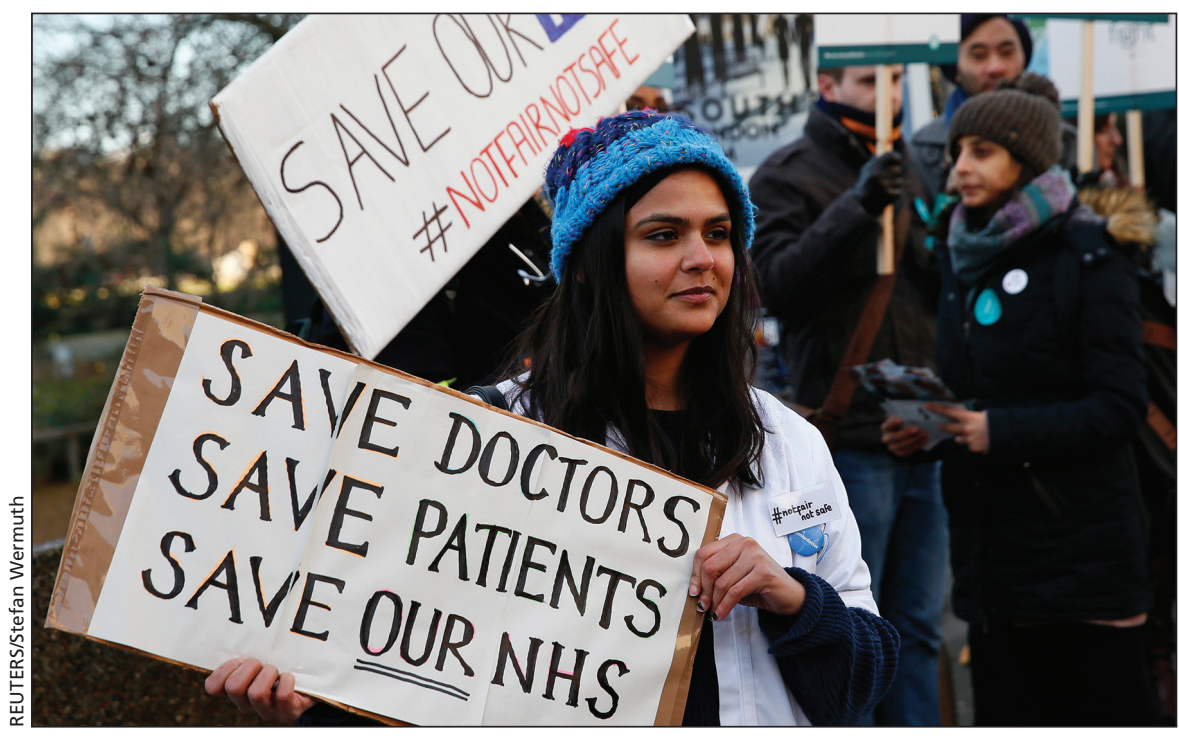

Doctors demonstrating outside St. Thomas' Hospital in London, England, as part of the first junior doctors' strike in $\mathbf{4 0}$ years.

cal care wards, according to the BMA. The BMA released guidelines for junior doctors, doctors and administrators responsible for scheduling - all well in advance of the strikes.

So does this make the strike actions safe and thus ethical? A recent article in the $B M J$, coauthored by Harvard research fellow David Metcalfe, concluded that in countries where strikes were well planned, there was no increase in patient deaths. In some cases, because of cancelled surgeries, the death rate fell.

In an interview, Metcalfe said that when physicians transition from autonomous professionals to employees, "it is almost inevitable that doctors starting to fight for their own rights are going to become more of an issue." While doctors might see their battle as against the government, they must also consider the rights of patients. They must find a balance. "That there was no increased loss of life during the strikes that we studied is an important part of that balance."

Although the BMA and NHS Trusts are ensuring patient safety, nonurgent services may be rescheduled, which means accepting that some patients will spend more time in pain if their surgeries are delayed. Metcalfe said, "It's hard to imagine a strike that causes no disruption whatsoever and yet still has its desired outcome. It's impossible to say that patients are not harmed at all. I think the question ought to be: Are they harmed in any way that is special to that relationship between doctors and patients?"

The strike has support from the health care community, including nurses and other professionals. Over 1000 NHS employees signed a Jan. 5 letter declaring their solidarity with junior doctors: "We too believe that industrial action is the only option now in order to protect our patients first and foremost from an unsafe contract that will see the junior doctors even more exhausted and demoralised than they already are." In a Jan. 11 press release, the BMA justifies the strike as a battle against "the first step in a wholesale attack on all NHS staff at night and over weekends." The strike is therefore not for personal gain but to protect the public's health care system.

Metcalfe is concerned that prolonged strike action might lead to a loss of public trust in the NHS. "That would be the biggest unfortunate aspect to come out of this dispute." - Debra Martens, London, UK

CMAJ 2016. DOI:10.1503/cmaj.109-5219 